REVISTA DE DERECHO UNED, NÚM. 10, 2012

\title{
EL CONTRATO DE OPCIÓN COMO CONTRATO ATÍPICO DE TRACTO ÚNICO: EXAMEN JURISPRUDENCIAL DE LA APLICABILIDAD DE LA RESOLUCIÓN POR EL CAMBIO O ALTERACIÓN DE LAS CIRCUNSTANCIAS
}

\author{
Rosa Adela Leonsegui Guillot \\ Profesora Titular del Departamento de Derecho Civil. UNED • *
}

Resumen: El contrato de opción, es un contrato sui generis con propia sustantividad y causa, oneroso o gratuito y consensual, por el que una de las partes (concedente) hace en favor de la otra parte (beneficiario u optante), o en favor de la persona que éste designe (en el supuesto de la opción mediatoria) una oferta irrevocable referida a un contrato final, válida durante un cierto plazo. El concedente queda vinculado, únicamente, al contrato proyectado y el optante adquiere el derecho preferente a decidir su definitiva conclusión. Entre sus características destacaremos, por sus consecuencias, su temporalidad en cuanto que el ejercicio del derecho de opción está sometido a un plazo de término, esto es a un lapso de tiempo que marca la vida de la opción.

Abstract: The option contract, is a contract sui generis with particulary and it causes, onerous or gratuitous and consensual, for the one makes of the other part (beneficiary), or in the person's favor that this designates, an irrevocable offer to a final contract, valid for a certain temp. The licensor is linked, only, to the projected contract and

- Grupo de Investigación Consolidado G-85 S17, «Protección civil de la persona», siendo Investigador responsable el Prof. Dr. D. Carlos Lasarte Álvarez, Catedrático de Derecho civil de la UNED.

" Este trabajo está dedicado al Maestro de Maestros, el Profesor Albaladejo, que en el momento de entregar estas líneas, nos comunicaron su reciente fallecimiento. 
the other one acquires the right to decide his definitive conclusion. Among their characteristics we will study that the exercise of the option right is subjected.

Palabras Clave: Contrato de opción; Resolución; Extinción; rebus sic stantibus

Key words: Option contract; Resolution; Extinction

Sumario: I. Planteamiento. II. Aspectos fundamentales del contrato de opción: concepto y caracteres. III. La controvertida naturaleza de la opción: de la concepción precontractual a la promesa unilateral. IV. Constitución y origen legal o convencional de la opción: requisitos. V. Influencia del cambio o alteración de las circunstancias contractuales sobre la opción: la doctrina de la cláusula rebus sic stantibus: 1 . El origen doctrinal y jurisprudencial de la cláusula rebus sic stantibus. 2. La diferenciación con la doctrina de la desaparición de la base del negocio, la imposibilidad sobrevenida, la frustración del fin económico del contrato y la causa. 3. La cláusula rebus sic stantibus como supuesto de integración contractual. 4. Requisitos y efectos de su aplicación. VI. Los contratos de opción en el tratamiento jurisprudencial de la cláusula rebus sic stantibus. VII. Inaplicabilidad a los contratos de opción de la doctrina jurisprudencial sobre la cláusula rebus sic stantibus: 1. La cláusula rebus sic stantibus y los contratos de tracto sucesivo. 2. La unilateralidad o bilateralidad de la opción y su repercusión sobre la aplicabilidad de la cláusula rebus sic stantibus. 3. Problemática en torno a la consideración del contrato de opción como resoluble implícitamente. 4. La imprevisibilidad y el carácter extraordinario de las circunstancias sobrevenidas. 5. Aleatoriedad y cláusula rebus sic stantibus. VIII. Reflexiones finales: la improbable aplicación de la cláusula rebus sic stantibus en los contratos de opción. IX. Bibliografía. X. Índice de sentencias del Tribunal Supremo.

\section{PLANTEAMIENTO}

Entre los negocios tendentes a una adquisición o enajenación futura que, por distintas circunstancias, aún no se quiere celebrar, destaca el contrato de opción. En este sentido, si el significado genérico de opción «es la libertad o facultad de elegir» ${ }^{1}$, jurídicamente, se refiere a la facultad concedida a determinada persona, durante algún

\footnotetext{
1 Diccionario RAE.
} 
tiempo, para obtener cierta prestación o ejercitar un derecho con preferencia a cualquier otra.

En el tráfico jurídico contemporáneo, la opción aparece incorporada a operaciones negociales de muy variada condición y procedencia: opciones de compra, venta, sobre préstamos, sobre accio$n^{2}{ }^{2}$, opciones arrendaticias, sobre terrenos mineros, concertadas a propósito de negocios de mediación (opción mediatoria), o de financiación, son, entre otros, ejemplos de la vitalidad de la figura que se ha convertido en la actualidad en uno de los instrumentos más idóneos en el campo de la contratación inmobiliaria y bursátil.

Pues bien, este profuso manejo de la opción explica la frecuencia con que el conflicto de intereses subyacente llegue hasta los Tribunales. En este artículo analizaré algunas de las cuestiones controvertidas que giran en torno al contrato de opción, centrándome en las consecuencias de su adscripción a los contratos denominados de tracto único y por tanto la difícil aplicabilidad de vías para obtener su resolución como por ejemplo la denominada cláusula rebus sic stantibus.

En su virtud, como cuestión previa parece conveniente analizar los elementos estructurales necesarios que permitan construir una figura jurídica con tipicidad social, por tratarse de un tipo contractual carente de regulación legal ${ }^{3}$, en el que su contenido está vinculado a la libertad de pacto. Por su parte, doctrina y jurisprudencia han concretado sus presupuestos y naturaleza ${ }^{4}$.

${ }^{2}$ Una opción es un contrato entre dos partes por el cual una de ellas adquiere sobre la otra el derecho, pero no la obligación, de comprarle o de venderle una cantidad determinada de un activo a un cierto precio y en un momento futuro. Existen dos tipos básicos de opciones: contrato de opción de compra (call) y contrato de opción de venta (put) que se desarrollan a través de cuatro estrategias elementales: compra de opción de compra (long call), venta de opción de compra (short call), compra de opción de venta (long put) y venta de opción de venta (short put).

3 Este contrato, como figura con individualidad propia, no fue considerado, en su momento, por los códigos. Así sucedía con el Código Civil francés de 1804, el español de 1889 y aún con los iberoamericanos más modernos, el mexicano de 1928, el venezolano de 1942, el boliviano de 1975, el paraguayo de 1985, el cubano de 1987; por su parte el Código Civil peruano de 1984, lo regula correcta y sistemáticamente en los arts. 1.419 a 1.424 bajo el nombre de "contrato de opción»; el nuevo Código civil brasileño de 2002, frente a la omisión precedente, dedica una nueva sección denominada «Do contato preliminar» (arts. 462 a 466). En algunos países, en legislación especial y paralela al Código se haya tipificado el contrato de opción. Así ocurre en Colombia por Ley 51/1918, y en Cuba por Decreto-Ley 888/1935.

${ }^{4}$ Para un estudio de la abundante jurisprudencia del Tribunal Supremo sobre el particular en los últimos años, vid TALMA CHARLES: «Crónica jurisprudencial sobre el contrato de opción relativa a la década de los noventa», $R d P$, año I, núm. 2, 1999, págs. 557-578. 
En el entendido de que la opción es una figura sui generis con sustantividad propia y causa diferente del contrato final ${ }^{5}$, es imprescindible que se delimite el contenido del futuro contrato y se conceda a una de las partes el derecho o facultad de poder perfeccionarlo por su exclusiva voluntad. Por tanto, todas las promesas que no contengan tal facultad y en las que se precise un posterior acto de asentimiento, habrán de ser calificadas de precontratos o promesas unilaterales de contrato, pero nunca constituirán una verdadera opción. De modo que el negocio básico (con sustantividad propia) y derecho originado son los dos aspectos que, en íntima conexión, conforman el fenómeno de la opción ${ }^{6}$.

\section{ASPECTOS FUNDAMENTALES DEL CONTRATO DE OPCIÓN: CONCEPTO Y CARACTERES}

A pesar de que su aspecto registral está reconocido en el art. 14 del $\mathrm{RH}^{7}$, la circunstancia de que la opción carezca de una regulación propia en el Código Civil, la doctrina y la jurisprudencia del Tribunal Supremo lo considera un contrato atípico. Se trata de un contrato «sui generis» con propia sustantividad y causa, oneroso o gratuito y consensual, por el que una de las partes (concedente) hace en favor de la otra parte (beneficiario u optante), o en favor de la persona que éste designe (en el supuesto de la opción mediatoria) una oferta irrevocable referida a un contrato final, válida durante un cierto plazo, de manera que únicamente el concedente queda vinculado con relación al contrato proyectado y el optante adquiere el derecho preferente a decidir con absoluta libertad en torno a la definitiva conclusión del mismo.

5 En este sentido se manifiestan las SSTS de 8 de marzo de 1991, 22 de diciembre de 1992, 14 de febrero de 1997 y 14 de febrero de 1995.

6 Vid. LORENZO MERINO: La opción de compra en el Derecho español, Santiago de Compostela, 1992, pág. 14.

7 El art. 14 del RH permite la inscripción de la opción de compra en el Registro de la propiedad siempre que se cumplan los siguientes requisitos: un convenio expreso de las partes para que se practique la misma; el precio estipulado para la adquisición de la finca, y en su caso el que se hubiere convenido para conceder la opción; y el plazo de ejercicio de la misma que no podrá exceder de 4 años. En relación con este último requisito la DGRN de 30 de julio de 1990 sostiene que el plazo de caducidad de 4 años recogido en el art. $14 \mathrm{RH}$ se refiere no al asiento registral, sino al propio derecho de opción. En contra la doctrina ha sostenido que el plazo de la opción, a efectos sustantivos, puede ser todo lo largo que se quiera (la STS de 6 de junio de 1959 se refiere a un caso en el que el plazo pactado era de 30 años), por lo que cabría concluir afirmando que el plazo establecido en el art. $14 \mathrm{RH}$ tiene un alcance meramente registral y deja intacto el derecho sustantivo. Por lo que, vencido el plazo registral, simplemente se termina la protección dispensada hasta entonces por el Registro. 
Es consensual en cuanto se perfecciona por el mero consentimiento, principal en el sentido de que es una figura independiente y autónoma respecto al contrato definitivo, bien se configure la opción como negocio principal único o como integrante de una acumulación de negocios ${ }^{8}$. Oneroso o gratuito, pues las partes pueden convenir que a cambio del derecho que se concede a una de ellas (optante) ésta corresponda con una contraprestación económica. Es lo que se llama prima o señal de la opción, muy frecuente en el tráfico negocial, dado que opera a modo de elemento compensador por la pérdida temporal del poder dispositivo sobre la cosa que sufre el concedente de la opción. Y temporal en cuanto que el ejercicio del derecho de opción está sometido a un plazo de término, esto es a un lapso de tiempo que marca la vida de la opción.

Por tanto, el contrato de opción se caracteriza por incorporar una promesa unilateral, en cuya virtud el optante tiene la facultad de realizar un determinado acto jurídico, cuyo contenido vincula al promitente por la mera declaración de voluntad de aquél, siempre y cuando sea ejercitada en las condiciones establecidas en el contrato.

Si teóricamente el contrato de opción puede tener un amplio campo de aplicación, en la práctica su operatividad se circunscribe a la opción de compra y más raramente a la opción de venta9 ${ }^{9}$, como demuestra el análisis de algunas de las definiciones que el Tribunal Supremo ha formulado sobre la figura y que en su gran mayoría se refieren a la opción de compra.

Entre las más destacables está la Sentencia del Tribunal Supremo de 14 de febrero de 1995, que en su Fundamento jurídico tercero señala que la opción de compra: «consiste en conceder al optante, la facultad exclusiva de prestar su consentimiento en el plazo contractualmente señalado a la oferta de venta que, por el primordial efecto de la opción es vinculante para el promitente, quien no puede retirarla durante el plazo aludido, y una vez ejercitada la opción, oportunamente, se extingue y queda consumado y se perfecciona automáticamente el contrato de compraventa, ya que basta para la perfección de la compraventa con el optante, que se le haya comunicado la voluntad de ejercitar su derecho de opción».

8 Así lo configura la generalidad de la doctrina. Vid., entre otros, SERRANO ALONSO: «Nota sobre el derecho de opción», RDP, 1979, pág. 1139. En contra se manifiestan aquellos autores que siguiendo el criterio de Roca Sastre defienden su condición de simple pacto añadido a otro contrato.

9 Vid. LASARTE ÁLVAREZ: Principios de Derecho civil, tomo III, contratos, Madrid, 2011, pág. 21. 
Añadiendo las SSTS de 19 de abril de 1995 y 16 de octubre de 1997, en sus FF $2 .^{\circ}$ y $1^{\circ}$, respectivamente, que: «debe entenderse como tal aquel convenio en virtud del cual una parte concede a otra la facultad exclusiva de decidir la celebración o no de otro contrato principal de compraventa, que habrá de realizarse en un plazo cierto $\mathrm{y}$ en unas determinadas condiciones ${ }^{10}$.

A la concepción actual del derecho de opción se ha llegado tras una particular evolución que ha ido perfilando sus contornos y dotándolo de una mayor perfección técnica, pero que todavía no ha terminado y que debería concluir, en opinión de algunos autores, con el pleno reconocimiento del derecho de opción como un verdadero derecho subjetivo patrimonial independiente del contrato originario ${ }^{11}$.

\section{LA CONTROVERTIDA NATURALEZA DE LA OPCIÓN: DE LA CONCEPCIÓN PRECONTRACTUAL A LA PROMESA UNILATERAL}

Como ya advirtiera en su día MEZQUITA DEL CACHO ${ }^{12}$ «desde el primer momento podemos decir que la cuestión crucial de la materia es la de su naturaleza», lo que ha determinado que la condición jurídica de la opción haya sido analizada con especial rigor y se vea sometida a constante debate. Pues los problemas de calificación suelen ser delicados y espinosos, dada la proximidad entre la opción y otras figuras afines: como los meros tratos preliminares, la oferta irrevocable, la promesa de contrato, el pacto de retro, los derechos de adquisición preferente.

A este respecto, la doctrina ha mantenido diversas opiniones, des-

10 En el mismo sentido vid. SSTS 24 de enero de 1991, FD 3..$^{\circ} 8$ de marzo de 1991, FD $4 .^{\circ} ; 14$ de mayo de 1991, FD $2 .^{\circ} ; 13$ de noviembre de 1992, FD 2..$^{\circ} ; 1$ de diciembre de 1992, FD 2. ${ }^{\circ} ; 22$ de diciembre de 1992, FD 4. ${ }^{\circ} ; 21$ de marzo de 1993, FD 1.. $; 18$ de junio de 1993, FD 2..$^{\circ} ; 21$ de junio de 1993, FD $6 .^{\circ} ; 22$ de septiembre de 1993, FD 4. ${ }^{\circ}$; 18 de octubre de 1993, FD 1..$^{\circ} ; 4$ de febrero de 1994, FD 3..$^{\circ} ; 14$ de febrero de 1995, FD $3 .^{\circ} ; 14$ de febrero de 1997, FD 2. ${ }^{\circ}$; 4 de diciembre de 1997, FD 1. ${ }^{\circ} ; 15$ de diciembre de 1997, FD 1.․

11 Así se manifiestan entre otros autores RAMÓN CHORNET: «Derecho de opción: cancelación de cargas ulteriores y breve apunte sobre su naturaleza real», $R C D I$ 1989, pág. 312; y LORENZO MERINO: La opción de compra en el Derecho español, pág. 14, quien pone de manifiesto que en el derecho de opción concurren los elementos esenciales que integran el concepto clásico del Derecho subjetivo: un titular determinado, una cosa perfectamente identificada como objeto y un poder independiente de electiva realización del derecho.

12 «El pacto de opción y el derecho que origina», RDCI 1951, pág. 77. 
de la llamada concepción tradicional o precontractual, pasando por la actual o renovadora, hasta llegar a la que diferencia entre la opción y determinadas promesas de contrato.

La teoría clásica sobre el precontrato y la opción surge en España a través de la conocida monografía de ALGUER: Ensayos varios sobre temas fundamentales de Derecho Civil IV. Los precontratos, publicada en el año 1931 en la Revista Jurídica de Cataluña; y otra posterior de MORO LEDESMA: El precontrato: notas para un estudio, publicada en la Revista Crítica de Derecho Inmobiliario, para quien inicialmente el precontrato "es un contrato que obliga a emitir una declaración de voluntad a una persona, que juntamente con la declaración que emita la otra parte integrarán los elementos del contrato obligacional principal que se proyecta».

Para la teoría clásica, si precontrato es una promesa de futuro contrato, el contrato de opción es esa misma promesa, pero cuyo objeto (el contrato definitivo) se somete a la libre decisión de un beneficiario. Una modalidad, por tanto, del primero. Concepción que llegó hasta bien mediado el S. XX, manifestándose en la obra de CASTÁN, ESPÍN y PUIG PEÑA. En todos ellos, el contrato de opción es contemplado como un reflejo del precontrato, es decir como un acto simplemente preparatorio que habrá de otorgarse ad futurum.

Las deficiencias del planteamiento clásico, como consecuencia del circuitos inutilis que comporta la repetición de consentimientos negociales, van a operar a modo de revulsivo provocando una exposición mucho más realista del negocio de opción. Y así, para DE CASTRO la opción no es algo que se agrega a otro contrato, sino una etapa previa con propia validez y eficacia. En la relación jurídica que puede desembocar en la relación contractual definitiva, hay que distinguir dos momentos: $1 .^{\circ}$ promesa de contrato, en la que se conviene el contrato proyectado y se crea la facultad de exigirlo, que funciona con cierta independencia en cuanto que tiene su propia causa; y 2. ${ }^{\circ}$ la exigencia del cumplimiento de la promesa de la que dimanarían los derechos y obligaciones concretos del contrato definitivo, cuya vigencia habría quedado mientras tanto en suspenso por haberse reservado las partes la facultad de exigir el cumplimiento contractual en un momento posterior a su puesta en vigor.

Y en segundo lugar, la idea de DE CASTRO sobre los dos distintos momentos en el iter negocial permite aplicar la norma del art. 1.451 del Código Civil a cualquier fórmula de opción. En su opinión hay que distinguir un primer momento negocial de promesa de compra o venta, y un segundo momento -tras la exigencia del cumplimiento- 
en que se constituirá la relación obligacional como verdadera compraventa, dando derecho a los contratantes para reclamarse recíprocamente el cumplimiento del contrato.

Finalmente, se encuentran aquellas posturas que defienden una completa distinción entre la opción y las promesas de contrato, tanto la bilateral como la unilateral. La diferenciación de la promesa o precontrato bilateral nace de la propia reciprocidad obligacional de ésta, de la duplicidad de promesas que concurren en el mismo negocio frente a la unicidad que configura la opción.

El problema surge con la promesa unilateral, máxime cuando la doctrina y la jurisprudencia mayoritaria configuran al precontrato como una relación jurídica única conformada ya en sus elementos esenciales y pendientes solamente de ejecución. Para algunos autores la respuesta al problema vendrá determinada por la consideración a que se someta tal promesa unilateral:

a. Si se la estructura como un contrato cuyo objeto sea celebrar el contrato proyectado, estaremos ante un precontrato en su modalidad unilateral.

b. Mientras que si se la estructura como contrato que posibilite el derecho a perfeccionar el definitivo por la simple aceptación de una de las partes intervinientes, estaremos ante la verdadera opción negocial.

Será, en definitiva, la común intención de las partes en orden a los efectos que persigan unida al dato objetivo de fijación de los elementos del futuro contrato, la que decidirá en cada caso a través de su interpretación cuál es la identidad que corresponde al negocio celebrado ${ }^{13}$.

\section{CONSTITUCIÓN Y ORIGEN LEGAL O CONVENCIONAL DE LA OPCIÓN: REQUISITOS}

El Derecho de opción puede tener origen legal ${ }^{14}$ o convencional, si bien tiene, normalmente, origen convencional en virtud de acuerdo o

13 Para un estudio de las diferentes concepciones doctrinales sobre la opción, vid., entre otros, CASTÁN: Derecho civil español, común y foral, IV, Madrid, 1988, págs. 27 y ss.; PUIG PEÑA: Compendio de Derecho civil español, III, 3. ${ }^{a}$ ed., Madrid, 1976, pág. 443; LALAGUNA: «La función negocial de la promesa de venta», $R C D I$, 1969, pág. 56; JERÓNIMO GONZÁLEZ: «El llamado Derecho de opción», RCDI, 1932, págs. 188 a 204; DE CASTRO: «La promesa de contrato», $A D C$, III, 1950, pág. 1166; y OSORIO Y GALLARDO: El contrato de opción, 2. ${ }^{\text {a }}$ ed., México, 1963, págs. 60 y ss.

${ }^{14}$ En el Ordenamiento jurídico español son escasos los supuestos claros de derecho 
pacto de los interesados. Este acto constitutivo puede ser inter vivos o mortis causa, ya sea oneroso o gratuito ${ }^{15}$.

Para que el acto constitutivo sea eficaz es preciso, según reiterada jurisprudencia del $\mathrm{TS}^{16}$ que concurran los siguientes requisitos:

1. El derecho unilateral del optante a decidir sobre el contrato final. La aceptación del optante se materializa no solo con el ejercicio en tiempo y forma de la opción, sino que esa manifestación de voluntad, dada la naturaleza recepticia de la figura, tiene que llegar a conocimiento del concedente dentro del susodicho plazo, ya que debe conocer si ha quedado libre o no de disponer de la cosa objeto de la opción, y porque hasta la finalización del plazo dura su vinculación con el optante ${ }^{17}$. Siendo preciso destacar a este respecto que tras la Ley 34/2002, de 11 de julio, que modifica el art. 1.262 del Código Civil, si el contrato de opción hubiese sido celebrado mediante dispositivos automáticos hay consentimiento desde que se manifiesta la aceptación.

2. $\quad$ La determinación del objeto. Una de las particularidades de la opción consiste en que su objeto abarca, no solo la materia propia de dicho contrato, sino que también el objeto de la opción se deberá referir también al objeto propio del contrato final de compraventa, esto es a la cosa vendida y al precio de la venta.

de opción de origen legal. La opción legal se vincula, en esencia, a determinadas áreas del Derecho agrario y del Derecho mercantil y muy marginalmente en Derecho civil. Dentro del Derecho agrario se citan el acceso a la propiedad que se establece en los arts. 184 y ss. de la derogada Ley de Arrendamientos Rústicos de 31 de diciembre de 1980. Y en Derecho civil los casos previstos en el Código Civil sobre redención de ciertos derechos reales -tales como censos, foros y subforos- en los arts. 1.608 a 1.612, 1.650 y 1.651 .

15 En tal sentido se expresa la Ley 460-2. ${ }^{\circ}$ de la Compilación Navarra: «Pueden constituirse por actos inter vivos o mortis causa a título oneroso o lucrativo, bien por constitución directa mediante enajenación o concesión, bien mediante renuncia o retención en un acto de transmisión de la propiedad». Por su parte, el art. 23 de la Ley Catalana 22/2001, de 31 de diciembre, que regulaba los derechos de superficie, de servidumbre y de adquisición voluntaria o preferente: «Los derechos de adquisición pueden constituirse por actos entre vivos, a título oneroso o gratuito, o por causa de muerte, mediante cesión, reserva o división». Y la vigente Ley 5/ 2006 de 10 de mayo, del Libro quinto del Código Civil de Cataluña, relativo a derechos reales en su art. 568-5.1 dispone que «Los derechos de adquisición pueden constituirse por cualquier título».

${ }_{16}$ Vid. SSTS: 13 de noviembre de 1992; 1 de diciembre de 1992; 18 de junio de 1993; 15 de octubre de 1993; 13 de noviembre de 1992; 19 de abril de 1995; 16 de octubre de 1997; 15 de diciembre de 1997.

17 Ello se advierte en las SSTS de 1 de diciembre de 1992; 8 de octubre de 1993; 25 de abril de 1994; 24 de abril de 1995; y 14 de febrero de 1997, cuando manifiestan que: «es necesario que esa declaración de voluntad llegue al concedente de la opción dentro del plazo». 
3. $\quad$ El plazo señalado para poder ejercitar la opción. Siendo Principio General del Derecho la prohibición perpetua de disponer y consistiendo el derecho de opción en una limitación próxima a este tipo que se impone al propietario de una cosa, es preciso fijar una duración del citado derecho.

El art. 461 de la Compilación Navarra establece un plazo máximo de diez años si se constituye con carácter real, mientras que el art. 568-8 de la Ley 5/2006, de 10 de mayo, del Libro quinto del Código Civil de cataluña distingue entre el derecho de opción de naturaleza real que puede constituirse por un plazo máximo de diez años, y el derecho de opción de naturaleza personas, que puede ser objeto de prórroga sucesivas cada una de los cuales no puede exceder del plazo de 10 años.

En Derecho común no opera esta limitación de años, pero sí es preciso fijar una duración del derecho por ser éste de carácter temporal. Si bien nada impide con apoyo en la autonomía de la voluntad (art. 1.255 CC) y en el principio del favor negotii que el plazo inicialmente pactado pueda prorrogarse, como ha reconocido la STS de 29 de mayo de 1996 siempre que la prórroga no exceda el tiempo máximo establecido para el ejercicio del derecho. Dicho plazo de ejercicio es de caducidad y por tanto no es susceptible de interrupción de interrupción ${ }^{18}$, y no se confunde con el plazo para el ejercicio de la acción encaminada a proteger el derecho de opción ante los Tribunales, la cual está sometida a un plazo de prescripción (STS 29 de mayo de 1996).

En principio la duración del plazo concedido para poder optar lo fijan las propias partes contratantes. Pero en defecto de esta premisa y directa determinación tampoco habría mayores inconvenientes, pues lo podría delimitar el órgano jurisdiccional en aplicación del art. 1.128 del CC, como afirma la STS de 14 de mayo de 1991. Por otro lado, como señala la STS de 22 de abril de 2000, es necesario distinguir entre dos plazos: el de ejercicio de la opción y el de su pago efectivo, pago del precio que queda así pospuesto lógica y temporalmente al ejercicio de la opción.

4. $^{\circ}$ Fijación en el momento de su constitución del precio final de adquisición del bien o de los criterios para su fijación posterior. Tal exigencia es de tal valor que su omisión lleva consigo la nulidad del derecho, pues este dato no es posible deducirlo de ningún otro. Sin embargo nada impide que en el acto constitutivo se esta-

18 Vid. en este sentido las siguientes SSTS: 30 de junio de 1994; 14 de febrero de 1995; 24 de abril de 1995; 29 de mayo de 1996, y 14 de febrero de 1997. 
blezcan los criterios para una posterior determinación o incluso que la valoración o fijación del precio pueda dejarse al arbitrio de un tercero siempre y cuando la determinación se produzca con anterioridad al ejercicio del derecho de opción ${ }^{19}$.

Como establecen las SSTS de 10 de febrero de 1994 y 22 de abril de 2000, el cumplimiento de lo convenido no exige el pago del precio en el momento mismo del ejercicio de la opción. Por otro lado, la eficacia de los medios solutorios alternativos está admitida jurisprudencialmente, como el ingreso en cuenta corriente si resulta de utilidad para el acreedor (SSTS 23 de noviembre de 1987 y 24 de marzo de 1988), por lo que el depósito notarial de un cheque conformado con la cantidad estipulada en el contrato de opción puede interpretarse como cumplimiento de la estipulación de pago anticipado prevista en el contrato.

\section{INFLUENCIA DEL CAMBIO O ALTERACIÓN DE LAS CIRCUNSTANCIAS CONTRACTUALES SOBRE LA OPCIÓN: LA DOCTRINA DE LA CLÁUSULA REBUS SIC STANTIBUS}

En los contratos de tracto sucesivo o larga duración o ejecución diferida una alteración sobrevenida e imprevisible de las circunstancias relativas al contrato puede convertir en excesivamente gravosa la prestación que pesa sobre una de las partes. Ante semejante eventualidad, la doctrina y la jurisprudencia españolas han recurrido a la llamada cláusula rebus sic stantibus ${ }^{20}$ como remedio destinado a restablecer el equilibrio que inicialmente existió entre las partes contratantes. Según ella, por la voluntad implícita de las partes, en todos los contratos de tracto sucesivo se sobreentiende que existe una cláusula por virtud de la cual el contrato obliga mientras las cosas continúen

${ }^{19}$ La Compilación Navarra y la Ley catalana 22/2001, de 31 de diciembre, admitían esta interpretación al permitir ambas que se prevean «cláusulas de estabilización» del precio fijado y que el ejercicio del derecho se realice por el precio fijado o el que resulte según el procedimiento establecido para su determinación.

20 Según la generalidad de la doctrina es convención del Derecho romano que se entendía incluida tácitamente en todos los negocios jurídicos, afirmación que es negada por DÍEZ-PICAZO, quien sostiene que se originó en los estudios de los glosadores (BARTOLO al comentar algunos pasajes de la Glosa y de las Decretales, y posteriormente por BALDO) y resucitó por la Escuela del Derecho Natural Racionalista de los siglos XVI y XVIII, siendo sus más importantes expositores GROCIO y PUFFENDORF. Cfr. DÍEZ-PICAZO Y PONCE DE LEÓN: «La cláusula rebus sic stantibus» en Cuadernos de Derecho Judicial, Consejo General del Poder Judicial, Madrid, 1996, pág. 679. 
así (rebus sic stantibus) ${ }^{21}$. De modo que en caso de una extraordinaria modificación del entorno contractual el contrato no vincula a las partes, o al menos quedan sujetas a una nueva forma de ejercicio de la prestación acomodada a las exigencias actuales.

\section{El origen doctrinal y jurisprudencial de la cláusula rebus sic stantibus}

El origen remoto de la cláusula rebus sic stantibus, que en definitiva tiende a poner de relieve la influencia continuada de la causa en el equilibrio contractual, se puede encontrar en la obra de Santo Tomás (no se es infiel a las promesas si las condiciones cambian esencialmente, ya que aquellas se hacen «subintelectis debitis conditionibus«), Alciato (que alude a la especial naturaleza del contrato y al error como excepciones a la invariabilidad de la voluntad autonómica), Heineccio, Grocio, Cocceio o Domat (siendo en todos los convenios la obligación de uno fundamento de la del otro, si ocurre un cambio que deba suspender el cumplimiento pendiente, se sobreentiende por la voluntad tácita de las partes que el cumplimiento debe aplazarse hasta que el obstáculo se haya levantado, aunque el ejemplo que dé a continuación sea el del comprador que después de la venta descubre el riesgo de evicción, Lex loix civiles dans leur ordre naturel, 1735), o en nuestro derecho histórico, Castillo de Sotomayor (todo contrato o negocio se ha de entender siempre con la implícita cláusula rebus sic stantibus et aliquo de novo non emergentibus) y la generalidad de la doctrina patria anterior al CC.

Es la necesidad de certeza en la codificación y el monismo legalista en materia de fuentes del derecho lo que excluye del régimen legal de los contratos, con carácter general, figuras como la de la cláusula rebus sic stantibus, cuya virtualidad es la de alterar o suspender la eficacia de las obligaciones contractuales, excluyendo o atemperando sus condiciones de exigibilidad al apreciar una modificación extraordinaria de las circunstancias que, implícita o explícitamente, determinaron la voluntad negocial de las partes. Pero lo cierto es que así, sin espacio para ella, se configuran Códigos civiles como el

21 Para un estudio de esta cláusula vid., entre otros, CANDIL: La cláusula rebus sic stantibus, estudio de Derecho español, Madrid, 1946; OSTI: «La cossi detta clausola rebus sic stantibus nel suo sviluppo storico», Revista de Diritto Civile; LENEL: "La cláusula rebus sic stantibus», trad. de W. Roces en Revista de Derecho Privado, 1923, julio-agosto; DUALDE GÓMEZ: «De la cláusula rebus sic stantibus», Conferencia Colegio Notarial de Barcelona, 1942. 
español donde el principio de la autonomía de la voluntad y de la fuerza obligatoria de los contratos (arts. 1.091, 1.254, 1.251, $1.258 \mathrm{y}$ 1.278) no está ni compensado ni completado con el re conocimiento de esta cláusula implícita, a pesar de que la presencia y valor del principio causalista y las exigencias de la buena fe sirvan de fundamento a la importación de esta figura a partir, sobre todo, de la doctrina alemana.

En cuanto a su origen jurisprudencial, la primera sentencia del TS que se cita en relación con la cláusula rebus sic stantibus es la de 14 de Diciembre de 1940 que en un supuesto de contrato de suministro donde se alegaba la variación esencial e imprevisible del mineral de hierro después de 1937, aún sin mencionar la cláusula, afirma, respecto de aquel contrato otorgado con causa lícita que «no puede invocarse la inexistencia de causa como sobrevenida con posterioridad, porque siendo la causa en la concepción de nuestro CC uno de los elementos constitutivos del contrato, necesarios para darle nacimiento, hay que referir su existencia a ese elemento creador del vínculo, y la prolongación de la teoría de la causa, más allá del momento de la formación del contrato, invadiendo el terreno de otras figuras jurídicas más o menos relacionada con aquélla, pero que la desplazan de sus términos legales estrictos aún cuando guarde conformidad con algunas orientaciones de la moderna doctrina científica, no encuentra apoyo alguno en nuestra Ley civil vigente».

Pero la Sentencia clásica en la materia es la de 13 de junio de 1944, donde aún sin mencionar nominativamente la cláusula rebus sic stantibus la aplica (o un principio corrector semejante) a un contrato de compraventa de aceite otorgado en junio de 1936 y cuyo cumplimiento se exigió al finalizar la Guerra Civil. En el pleito se discutió si había existido una imposibilidad absoluta sobrevenida de ejecución del contrato o si por tratarse de cosas genéricas, la regla aplicable era la de que el género nunca perece:

«que la fuerza mayor dimanante de la Guerra, operando en obligaciones genéricas por ella afectadas, no produce en principio efectos extintivos por imposibilidad absoluta y permanente de cumplimiento, en atención a que el género no perece, pero produce corrientemente imposibilidad pasajera con efectos meramente suspensivos en aquellos casos en que al cesar la actuación de la fuerza mayor, revive la obligación contraída si llena entonces la finalidad buscada por los interesados al tiempo de la celebración del contrato, y en este aspecto bien se advierte que no hubo al producirse la liberación obstáculo insuperable para la entrega del género vendido en las condiciones pactadas, salvo en la referente a la fecha de la entrega que, en casos como el de 
autos, es requisito accidental, constitutivo de simple demora amparada con efectos liberatorios por la fuerza mayor (...)».

El TS llegó a esta conclusión, pero efectuó una revisión equitativa del contrato aplicando un principio corrector que frente a los orígenes de la cláusula en la voluntad implícita negocial de las partes, busca más su fundamento en razones objetivas, valorando en una situación extraordinaria y traumática, el principio de la buena fe y las exigencias de un ordenamiento causalista. Posteriormente son muchas las sentencias que han tratado de la cláusula rebus sic stantibus, admitiéndola expresis verbis como instrumento a través del cual la causa, con su exigencia de equilibrio contractual en las prestaciones, ejerce una influencia continuada sobre el contrato, hasta el punto de ser concebible su moderación o adecuación dejando la posibilidad de la dispensa o resolución para otras instituciones vinculadas a la cláusula y tributarias también de la continuada influencia de la causa, como la doctrina de la desaparición de la base del negocio.

Se ha ido generando así una doctrina jurisprudencial perfectamente organizada y consistente que al mismo tiempo destaca la extraordinaria cautela con que puede admitirse este remedio excepcional a los desequilibrios contractuales, como consecuencia de la extraordinaria e imprevisible alteración de las circunstancias que motivaron su otorgamiento y configura los requisitos que también excepcionalmente podrían justificar la aplicación de tal cláusula.

\section{La diferenciación con la doctrina de la desaparición de la base del negocio, la imposibilidad sobrevenida, la frustración del fin económico del contrato y la causa}

Para corregir el pretendido desequilibrio entre las prestaciones, la doctrina también ha acudido a la teoría de la excesiva onerosidad de la prestación concebida por los civilistas italianos (arts. 1.447-1.479 del CC italiano de 1942) y a la teoría de la desaparición de la base del negocio jurídico creada por OERTMANN y LARENZ para el Derecho alemán y seguida en nuestro Derecho por DÍEZ-PICAZO, y que sostiene que la base del negocio jurídico puede ser subjetiva y objetiva. La base subjetiva es la expectativa o representación mental de los fines del contrato esperados por las partes. En cambio, la objetiva es el conjunto de circunstancias y el estado general de las cosas, cuyo mantenimiento es necesario para que el contrato pueda seguir siendo el mismo. 
Pero lo cierto es que el TS las ha equiparado a todas ellas como mecanismos correctores del desequilibrio al afirmar que:

«Tanto la aplicación implícita de la cláusula de la cláusula rebus sic stantibus et aliquo novo non emergentibus, como la de la teoría más subjetiva de la quiebra o desaparición de la base del negocio, como la de equivalencia de las prestaciones o de la equidad al amparo del art. 3.2. ${ }^{\circ}$ del CC, no son sino distintos mecanismos que la jurisprudencia y la técnica doctrinal utilizan para enmendar el pretendido desequilibrio producido en el cumplimiento del contrato a lo largo del tiempo en que, de forma continuada, haya de producirse» (STS de 6 de octubre de 1987).

Aunque en otras sentencias posteriores las diferencia por razón de sus efectos: puramente revisores del contenido obligacional del contrato en la cláusula rebus sic stantibus o resolutorios en la doctrina de la desaparición de la base del negocio.

Con todo, según la jurisprudencia la mayor parte de las escasísimas sentencias que justifican el recurso a la aplicación de la cláusula rebus sic stantibus, lo hacen en supuestos que no son de modificación del valor económico de los bienes objeto del contrato, sino en supuestos en que la alteración extraordinaria de sus circunstancias ha consistido en la generación de un hecho singular determinante de la desaparición o gravísima afección del interés de una de las partes contratantes comprometiendo, ex post facto, la causa del contrato, y así la Sentencia de 20 de abril de 1994 que, aunque cita la doctrina de la cláusula rebus sic stantibus para dar cuenta del «influjo de circunstancias sobrevenidas e imprevistas en la vida del contrato» lo que realmente hace es estimar el recurso "por haber desaparecido la causa negocial durante el transcurso de la vigencia del contrato de tracto sucesivo", siendo éste un arrendamiento de una finca que tenía por objeto la extracción de guijo, y la misma deviene imposible.

Y en igual sentido, la Sentencia de 20 de febrero de 2001 que aplica la cláusula rebus sic stantibus para defender el pago del canon anual pactado en un contrato de constitución de derecho de superficie por 75 años y opción de compra durante determinado periodo de tiempo, coincidente con la vigencia de una anotación preventiva de demanda a favor del Estado impeditiva de la realización de las obras de construcción previstas en el contrato.

Todos ellos son supuestos en los que aunque se invoque la cláusula rebus sic stantibus, o formalmente se aplique porque se trate de justificar un efecto puramente modificador del contrato y no resolutorio, nos encontramos más cerca de la doctrina de la base del nego- 
cio por la generación de hechos singulares que afectan al interés de las partes y a la causa del contrato, y no por la mera alteración en el valor de las cosas que puede producir el paso del tiempo y en el que se han podido desencadenar fenómenos que incrementen o reduzcan extraordinariamente el valor de los bienes objeto del contrato o las prestaciones.

\section{La cláusula rebus sic stantibus como supuesto de integración contractual}

La solución que para el caso de alteración de las circunstancias contractuales aporta la teoría de la cláusula rebus sic stantibus no puede cohonestarse fácilmente con el principio pacta sunt servanda (los contratos son para cumplirlos) proclamado en el art. 1.091 del CC cuando dice que "las obligaciones que nacen de los contratos tienen fuerza de ley entre las partes contratantes y deben cumplirse a tenor de los mismos», pues su desconocimiento implicaría poner en peligro el principio de la seguridad jurídica contractual, la eficacia de la voluntad manifestada y el mantenimiento del orden jurídico orden jurídico ${ }^{22}$. Por ello la admisibilidad de la cláusula se hace con extraordinaria cautela imponiendo severas restricciones a su efectividad.

La confrontación entre el principio de seguridad contractual ( $p a c$ ta sunt servanda) y el mantenimiento de la equivalencia de las prestaciones (cláusula rebus sic stantibus) se ha pretendido resolver a favor de esta última, afirmando que dicha cláusula se encuentra ínsita en todo contrato por voluntad presunta de las partes ${ }^{23}$.

Sin embargo, dicho planteamiento es criticado por la doctrina por considerarlo erróneo y confuso ${ }^{24}$. Ya en 1923 la Revista de Derecho Privado presenta un trabajo de Otto Lenel, quien siguiendo a Krückmann señala como «las palabras rebus sic stantibus no aluden a una verdadera cláusula contractual, sino que son las normas de de-

${ }^{22}$ Cfr. SSTS de 16 de junio de 1983, 27 de junio de 1984, 19 de abril de 1985, 17 de mayo de 1986, y 6 de octubre de 1987.

${ }_{23}$ Para BARSANTI el contrato a largo plazo no puede tener significado jurídico sin la cláusula rebus sic stantibus, que es ideológicamente de igual naturaleza a similares géneros de contratos, es pues una auto limitación de la voluntad siempre sobreentendida. Cfr. TERRAZA MARTORELL: ob. cit., pág. 61.

${ }^{24}$ Para DÍEZ PICAZO es ficticia la relación existente entre la voluntad de las partes y los efectos que pueda producir la alteración sobrevenida. Por lo que no puede hablarse de una verdadera cláusula o de una voluntad presunta. Cfr. DÍEZ-PICAZO Y PONCE DE LEÓN: ob. cit., pág. 684. 
recho objetivo las que dan base para los efectos de esta llamada cláusula», refiriéndose sobre todo al principio de la buena fe y a la equidad como instancia normogénica ${ }^{25}$. La doctrina de la cláusula rebus sic stantibus se refleja seguidamente en las obras de Pérez González y Alguer, Castán Tobeñas, Badenes Gasset, Candil y Hernández Gil, y más tarde en la de Federico de Castro.

La virtualidad propia de la cláusula (adecuar el contenido contractual a las nuevas circunstancias o declarar su eficacia para el futuro) no se deriva pues de pacto alguno, ni de la voluntad presunta de las partes, se trata sencillamente de una aplicación concreta a los contratos de ejecución temporalmente diferida de las reglas de integración contractual establecidas imperativamente por el art. 1.258 del $\mathrm{CC}^{26}$ que, por principio, son indisponibles para la voluntad de las partes $^{27}$.

\section{Requisitos y efectos de su aplicación}

Los pronunciamientos del Tribunal Supremo revisten en relación a la cláusula rebus sic stantibus una importancia capital, toda vez que la elaboración funcional de la citada cláusula tiene indudablemente un origen jurisprudencial, a excepción de Navarra que en el Fuero Nuevo contiene norma expresa que regula los efectos y aplicación de la cláusula en la ley 493.3 que dispone: «cuando se trate de obligaciones de largo plazo o tracto sucesivo, y durante el tiempo de cumplimiento se altere fundamental y gravemente el contenido económico de la obligación o la proporcionalidad entre las prestaciones, por haber sobrevenido circunstancias imprevistas que hagan extraordinariamente oneroso el cumplimiento para una de las partes, podrá ésta solicitar la revisión judicial para que se modifique la obligación en términos de equidad o se declare su resolución ${ }^{28}$.

${ }^{25}$ Como dice VON THUR «es contrario a la bona fides obligar al deudor a respetar el contrato cuando las condiciones se han modificado de tal manera que, caso de cumplirlo, no obtendría contraprestación alguna u obtendría una contraprestación perfectamente insignificante».

26 «Los contratos se perfeccionan por el mero consentimiento, y desde entonces obligan, no solo al cumplimiento de lo expresamente pactado, sino también a todas las consecuencias que, según su naturaleza sean conformes a la buena fe, al uso y a la ley».

27 Cfr. LASARTE ÁLVAREZ: ob. cit., pág. 171.

28 «La doctrina relativa a la cláusula rebus sic stantibus, sancionada en el párrafo tercero de la ley 493 del Fuero Nuevo, que trae su causa próxima de la ley 508 de la Recopilación Privada y su causa remota del Fuero General y Fueros de la Novenera y de la 
El ámbito de aplicación de la cláusula en Navarra, salvo en la previsión tendente a declarar la modificación de la obligación o su resolución, es prácticamente coincidente con cuanto viene estableciendo reiterada jurisprudencia del Tribunal Supremo, que exige extraordinaria cautela en cuanto a su aplicación y que se traduce en la observancia de unos requisitos sumamente rígidos que son los siguientes:

1. ${ }^{\circ}$ Alteración extraordinaria de las circunstancias en el momento de cumplir el contrato en relación con las concurrentes al tiempo de su celebración.

2. $\quad$ Una desproporción exorbitante, fuera de todo cálculo, entre las pretensiones de las partes contratantes, que verdaderamente derrumben el contrato por aniquilamiento del equilibrio de las prestaciones.

3. Que todo ello acontezca por la sobreveniencia de circunstancias radicalmente imprevisibles.

4. ${ }^{\circ} \quad$ Y que se carezca de otro medio para salvaguardar y remediar el perjuicio ${ }^{29}$.

En torno al ámbito de aplicación de la cláusula hemos de destacar que, en principio, resulta admisible respecto de todo contrato de tracto sucesivo o ejecución diferida con prestaciones recíprocas pendientes a cargo de ambas partes en los que las partes no han previsto o pactado ningún mecanismo de modificación del valor de las prestaciones y siempre que concurran todos los requisitos que acabamos de citar. Y en cuanto a las consecuencias de la aplicación de la cláusula rebus sic stantibus, el Tribunal se inclina por revisar o modificar la originaria equivalencia de las prestaciones, y a estos efectos declara que:

«Hasta el presente se le han negado los rescisorios, resolutorios o extintivos del contrato, otorgándole solamente los modificativos del mismo, encaminados a compensar el desequilibrio de las prestacio-

\footnotetext{
jurisprudencia que avala la expresada doctrina, autoriza a decir sobre ella: $1 .^{\circ}$ Que desenvuelve un fundamento subjetivo a la modificación del contrato, basándola en la propia voluntad de los contratantes; $2 .^{\circ}$ que, aunque como precedentes se señalan algunos textos del Derecho romano, en realidad procede de la doctrina y práctica forense de los tiempos medievales, olvidada por los Códigos francés, italiano y español y reavivada tras la Primera Guerra Mundial...», SAT 26.3. 76.

${ }_{29}$ Cfr., entre otras, SSTS de 17 de mayo de 1957, 6 de junio de 1959, 27de junio de 1984, 17 de mayo de 1986, 6 de octubre de 1987, 27 de junio de 1993, 29 de mayo de 1996, 15 de noviembre de 2000, y 20 de febrero de 2001.
} 
nes u obligaciones» (SSTS 17 de mayo de 1957, 23 de abril de 1991, y 20 de febrero de 2001).

\section{LOS CONTRATOS DE OPCIÓN EN EL TRATAMIENTO JURISPRUDENCIAL DE LA CLÁUSULA REBUS SIC STANTIBUS}

Las primeras sentencias que en España trataron el tema de la posible aplicación de la cláusula rebus sic stantibus al contrato de opción datan de los años 40. Así, en Sentencia de 5 de junio de 1945 el TS decide que no puede oponerse la doctrina de la cláusula al ejercicio de una opción de compra insertada en un arrendamiento de duración de doce años por la considerable elevación de los precios y la debilitación de la moneda, en un caso en el que el contrato era de 1929 y su ejecución se pretendía en 1941.

En la STS de 6 de julio de 1959 se vuelve a considerar inaplicable la cláusula a un contrato de arrendamiento con opción de compra, en este caso de un hotel (el Hotel Continental Palace de San Sebastián) pactado en 1921 y ejercitado en 1951, mediando una importantísima alteración de las condiciones o circunstancias económicas. Y el TS afirma que tal alteración debería quedar subsumida en el aleas inherente a toda opción de compra, y prosigue abordando el problema de la imprevisión o previsión contractual subordinándose la cláusula rebus sic stantibus a la voluntad negocial concreta. La opción se ejercita y el Tribunal la acepta por el precio de 5 millones de pesetas pactado en 1921. Prevalece el principio pacta sunt servanda», pues desde su iniciación en el año 1921 el contrato sufrió diversas modificaciones, todas ellas pactadas por las partes, y en ellas no se modificó el precio de la opción, lo que demuestra la voluntad de mantener lo pactado cuando la devaluación de la moneda era un hecho de todos conocido.

La jurisprudencia posterior sigue la misma línea restrictiva. Se reitera la doctrina de que la cláusula rebus sic stantibus no es aplicable a una opción de compra por entenderla contraria a la voluntad de unas partes que conocían perfectamente el objeto contractual y no quisieron hacer variable el precio del mismo (STS 26 de octubre de 1990). Tampoco se aplica a un arrendamiento con opción de compra, "ya que el aumento del valor de la finca objeto de la opción de compra no puede calificarse por sí solo de alteración completamente extraordinaria ni menos aún puede reputarse consecuente a circunstancias radicalmente imprevisibles", máxime cuando sí se previó el 
incremento del precio de ejercicio de la opción según cuando tuviere lugar (STS 29 de mayo de 1996).

Todas estas sentencias tienen como denominador común que las razones en que basan el rechazo a la aplicabilidad de la cláusula rebus sic stantibus a los contratos de opción se vinculan a su estructura obligacional y causal.

\section{INAPLICABILIDAD A LOS CONTRATOS DE OPCIÓN DE LA DOCTRINA JURISPRUDENCIAL SOBRE LA CLÁUSULA REBUS SIC STANTIBUS}

Sobre el general carácter restrictivo con el que la jurisprudencia admite la cláusula rebus sic stantibus, concurren tratándose de un contrato de opción determinados rasgos que dificultan, aún más si cabe, la eventual aplicación de la cláusula y que a continuación pasamos a examinar:

\section{La cláusula rebus sic stantibus y los contratos de tracto sucesivo}

En primer lugar, la cláusula está históricamente vinculada a los contratos de tracto sucesivo, caracterizados por prestaciones continuadas a cambio de contraprestaciones periódicas durante un periodo dilatado de tiempo que posibilita la interferencia de alteraciones extraordinarias que comprometan la causa contractual y conlleva mayores exigencias de conmutatividad, prestación con contraprestación en cada momento de la vida del contrato, de modo que la propia continuación de su eficacia se justifica en el mantenimiento del equilibrio contractual, frente al carácter puntual o unitario del intercambio de prestación y contraprestación en los contratos de tracto úni$\mathrm{co}^{30}$

Pues bien, el contrato de opción no es un contrato de tracto sucesivo, sino de tracto único por el que una de las partes concede a otra la facultad exclusiva de decidir la celebración o no de otro contrato

30 Sobre la denominada "cinemática de la relación obligatoria», vid. MORETÓN SANZ, «Examen crítico de los fundamentos dogmáticos y jurisprudenciales de la expromisión y del artículo 1.205 del Código civil español (La vicenda modificativa, la sucesión singular de las deudas, el programa de la prestación y la aplicabilidad de ciertos principios contractuales«), Anuario de Derecho Civil, tomo LXI, fas. II, 2008, pág. 627 y 628 . 
que habrá de realizar en un plazo cierto y en unas determinadas condiciones. El ejercicio tempestivo y correcto de la opción (esto es, dentro del plazo pactado) oportunamente notificado al concedente (dado su carácter receptício) consuma y extingue el contrato de opción y en ese preciso instante nace y se perfecciona automáticamente el correspondiente contrato final sin que el concedente de la opción pueda hacer nada para frustrar su efectividad, pues en el contrato de opción el contrato definitivo está plenamente configurado y depende únicamente del optante que se perfeccione o no (STS 14 de febrero de 1997).

En realidad, al configurar la opción, el concedente prestó anticipada e irrevocablemente su consentimiento al contrato definitivo; ejercitado el derecho de opción en tiempo y forma oportunos, el optante está completando el concurso de voluntades necesario para que pueda nacer y perfeccionarse automáticamente el contrato proyectado (SSTS de 8 y 16 de octubre de 1997). Lo que sucede es que en él existe una dilación temporal, en cuanto a la opción, entre el momento de su establecimiento y el momento de su ejercicio, como es de esencia en este tipo de contratos, y que ha inducido en ocasiones a confundirlo con el tracto sucesivo.

En segundo lugar, tratándose de contratos de tracto único la jurisprudencia del TS (SSTS de 23 de abril de 1991, 10 de febrero de 1997 y 28 de diciembre de 2000, entre otras) ha declarado que el conjunto de requisitos exigidos para la aplicabilidad de la cláusula rebus sic stantibus entraña una excepcionalidad todavía más acusada en esta clase de contratos.

Por otro lado, los contratos de tracto único plantean un problema adicional para convertirse en ámbito de aplicación de la cláusula rebus sic stantibus por alteración extraordinaria de las circunstancias que motivaron su otorgamiento: la exclusión en el CC de la rescisión por lesión al prescribir el art. 1.293 que «ningún contrato se rescindirá por lesión fuera de los casos mencionados en los números 1 y 2 del art. 1.291 (contratos celebrados por los tutores o en representación de los ausentes). Es cierto que rescisión por lesión y cláusula rebus sic stantibus son técnicamente figuras distintas, por cuanto la primera atiende a la desproporción entre las prestaciones de las partes que pueda existir en el momento de la perfección del contrato, en tanto que la segunda entraría en juego por la lesión producida por un hecho posterior a la celebración del mismo. Pero en los contratos de tracto único donde la dilación temporal de su cumplimiento obliga a remitirse a una o ambas partes al consentimiento ya prestado ini- 
cialmente, como sucede en la opción de compra con el consentimiento del concedente, es en aquel momento originario del otorgamiento en el que debe medirse el equilibrio contractual de las prestaciones, ya que el riesgo de variación del valor ha de entenderse asumido por el concedente de la opción en los términos que posteriormente desarrollaremos.

\section{La unilateralidad o bilateralidad de la opción y su repercusión sobre la aplicabilidad de la cláusula rebus sic stantibus}

La admisión por la jurisprudencia de la cláusula rebus sic stantibus se ha producido de forma extraordinariamente restrictiva, referida a los contratos de tracto sucesivo con prestaciones pendientes a cargo de ambas partes contratantes. El contrato de opción, en cuanto exige la concurrencia de voluntades, se presenta en su origen como de naturaleza bilateral, con la necesaria observancia de los arts. 1.261 y concordantes del Código Civil. Por tanto, como contrato es bilateral desde el punto de vista de las declaraciones de voluntad, pero es unilateral desde el punto de vista de las obligaciones producidas. Su bilateralidad originaria será elemento diferenciador frente a la oferta revocable; su unilateralidad en la obligación lo será frente a la promesa bilateral de compra y venta.

El problema surge en el supuesto de que las partes hayan pactado la obligación de pagar una prima a cargo del optante. Habitualmente la doctrina ${ }^{31}$ y alguna sentencia del Tribunal Supremo ${ }^{32}$ creen que en este caso el contrato unilateral de opción se convierte en bilateral dada la correspondencia de obligaciones contractuales. En este caso la cuestión hay que focalizarla en si la asignación de un precio a la opción la configura automáticamente como negocio jurídico bilateral o recíproco y lo incluye en la órbita del art. 1.124 del Código Civil. Y por tanto como resoluble implícitamente.

\section{Problemática en torno a la consideración del contrato de opción como resoluble implícitamente}

Afirma HERNÁNDEZ GIL al enjuiciar (desde la perspectiva de

31 Vid., entre otros, BONET RAMÓN: Comentarios al Código Civil de Mucius Scaevola, XIII, I, 2. ${ }^{\text {e }}$ d., Madrid, 1970, pág. 556; y PUIG PEÑA: Compendio..., ob. cit., pág. 444.

32 Cfr. STS 22 de diciembre de 1992, FD 6. . 
que el derecho a exigir el cumplimiento del contrato definitivo lo tiene solo una de las partes) el supuesto de que se pacte una indemnización a cargo del optante para el caso de que no se ejercite el derecho, introduce una dualidad de prestaciones, pero no una verdadera reciprocidad entre ellas; el deber de prestar y el deber de exigir no son correlativos. Considera, por tanto, para este supuesto concreto de indemnización que frente al derecho del optante (elemento configurador de la relación opcional) solo cabe situar el deber de la otra parte.

Sobre la aplicación del art. 1.124 CC a las opciones de compra, el TS no se ha manifestado de una manera definitiva y decidida. En Sentencia de 29 de junio de 1987 (contempla un supuesto de no ejercicio de derecho de opción y contiene la aportación de que al haber mediado asignación de un precio a la opción parece configurarla de bilateral e incluirla, en principio, en la órbita del art. 1.124 del Código Civil. Y en Sentencia de 30 de septiembre de 1989 declara que a los efectos debatidos es inaplicable el art. 1.124 a esa opción de compra por su naturaleza de contrato unilateral en este caso concreto y referirse dicho precepto a obligaciones recíprocas. Lo que nos lleva a una breve reflexión sobre la reciprocidad y sus elementos. En las obligaciones recíprocas cada parte asume un deber de prestación a título de contrapartida por la retribución de la otra parte. No basta que se den las obligaciones de ambas partes frente a frente, o como decía HERNÁNDEZ GIL dualidad de prestaciones, sino que es necesario que exista entre ellas mutua condicionalidad, que la prestación de cada parte sea condición implícita o constructiva de la otra. Es decir, tienen por contenido un sinalagma doble: genético, en cuanto una atribución patrimonial debe su origen a la otra, y funcional por la interdependencia que las dos atribuciones tienen entre sí.

Considerando estas características del sinalagma, no parece defendible que la opción como negocio jurídico de carácter unilateral se convierta en bilateral o recíproco por el simple hecho de que concurra en él el elemento accesorio del pago de una prima, pues como sostiene la Sentencia del Tribunal Supremo de 29 de marzo de 1993, la prima no es un requisito esencial, por lo que el incumplimiento en cuanto a su pago no puede desencadenar, por sí solo, el mecanismo resolutorio previsto en el art. 1.124 del Código Civil. Por tanto, estos contratos de opción podrían ser calificados de onerosos (al intervenir la prima) y con una unilateralidad desvirtuada, como dice HERNÁNDEZ GIL, confirmando la esencial naturaleza unilateral del contrato de opción y su exclusión del régimen del 
art. 1.124 del CC. En consecuencia, no son resolubles implícitamente, y en el hipotético caso que el TS admitiera la aplicación de la cláusula rebus sic stantibus, sus efectos serían puramente revisores del contenido obligacional del contrato y no resolutorios.

\section{La imprevisibilidad y el carácter extraordinario de las circunstancias sobrevenidas}

La consideración de conjunto de las sentencias del Tribunal Supremo que han ido construyendo la doctrina de la cláusula rebus sic stantibus sobre la base del carácter extraordinario de las circunstancias extraordinarias que sobrevienen durante la vida de un contrato de tracto sucesivo y que afectan al interés de las partes, al fin del contrato y a su causa, exigen que ese calificativo de extraordinario, excepcional, e imprevisible sea interpretado no solo en términos de medida para denotar el grado de alteración de las circunstancias contractuales que ha producido, o lo poco previsible que era, sino en términos que singularicen el supuesto contractual concreto de que se trata y lo diferencien de los demás en el tráfico jurídico.

La jurisprudencia ofrece argumentos para esta interpretación, en mayor o menor grado, unas veces con la superposición de calificativos referentes a las circunstancias, al desequilibrio contractual o a la imprevisibilidad, que necesariamente deben llevar a acotar el supuesto en su singularidad, y otras veces de forma más explícita, como la Sentencia de 6 de noviembre de 1922 que exige que sean "atendidas las circunstancias particulares de cada caso concreto" para identificar la cabal medida de lo extraordinario».

Refiriéndose al carácter imprevisible del suceso que puede determinar la aplicación de la cláusula, el Tribunal Supremo ha señalado que:

«(...) el evento que las partes pudieron evitar estableciendo convencionalmente los remedios oportunos en los contratos de tracto sucesivo (...), tales como la revisión periódica del contrato, o cláusulas de estabilización y pago en especie para garantizar al acreedor de la prestación pecuniaria que la cantidad a recibir no resultaría afectada por la disminución del poder adquisitivo de la moneda, no pueden integrar alteración extraordinaria imprevista e imprevisible» (STS de 15 de marzo de 1972).

De donde puede deducirse que en ningún caso será de aplicación la cláusula cuando las partes hayan previsto o pactado algún mecanismo de modificación del valor de las prestaciones (como cláusulas 
de variación del precio), excluyendo así otros factores de variación y que las variaciones exógenas de valor pudieran reputarse absolutamente imprevistas o imprevisibles. Pues bien, va a ser precisamente este requisito de la imprevisibilidad el principal escollo con el que tropieza la opción para que le pueda ser aplicada la referida cláusula. El derecho de opción proporciona a su titular una situación de libertad contractual dentro de los estrictos términos de una alternativa y correlativamente coloca al concedente en una situación de incertidumbre. De aquí la extraordinaria dificultad de acreditar en forma racionalmente contundente y decisiva, como exige el TS, que «todo acontezca por la sobreveniencia de circunstancias radicalmente imprevisibles» (STS 6 de noviembre de 1992).

\section{Aleatoriedad y cláusula rebus sic stantibus}

Hoy, el aleas en sentido jurídico o el riesgo en sentido económico está más presente que nunca en la vida de la contratación porque los bienes y factores económicamente significativos se han multiplicado e interconectado, produciendo como consecuencia que cambios sutiles en los escenarios macroeconómicos provoquen enormes diferencias de valor. Además, el aleas o el riesgo se introduce en el tráfico jurídico constituyendo un valor por sí mismo, objeto del tráfico.

No solo se asumen obligaciones diferidas en el tiempo con tipos de interés variables indexados, sino que se hacen contratos de futuros, derivados, cuyo valor está representado por la estimación, y el valor que en el mercado se da a la estimación, de un determinado valor futuro para un bien o un tipo de bienes de referencia.

Los contratos de opción, dado su carácter temporal, por definición entrañan una cierta asunción de los riesgos. Todas las opciones tienen un componente de predeterminación (plazo y precio) y un componente de variabilidad o aleatoriedad, que tratándose de opciones de compra o venta de acciones será por referencia al valor presente, real o de mercado al vencimiento, que es inherente a la estructura contractual. Adicionalmente, la existencia de dos opciones recíprocas de venta y de compra en condiciones simétricas o similares, tanto en cuanto al precio de ejercicio como al vencimiento final, implican una asunción simétrica y equilibrada por ambas partes de los riesgos de variación del valor de los bienes objeto de la opción, por lo que en tal caso deberá prevalecer el equilibrio originario entre 
ambas frente a la sobreveniencia de hechos posteriores que puedan desigualar el valor de algunas de las prestaciones.

El Tribunal Supremo se ha ocupado en numerosas sentencias del problema del cambio de la normativa urbanística sobrevenida a la celebración de un contrato de opción como evento que debe integrarse dentro del aleas o riesgo que supone cualquier operación realizada a plazo. Veamos con qué alcance.

La STS de 24 de junio de 1993 se refiere a un supuesto de opción de compra entre «Somosaguas Sur, S.A.» y «Urbanizadora Somosaguas, S.A.», que en el clausulado contractual habían establecido una condición suspensiva, en cuya virtud, en caso de no consumarse la compraventa se habría de devolver la cantidad entregada, con un $11,75 \%$ de interés anual durante el primer año y el MIBOR más 0,50 puntos durante el resto del periodo hasta su devolución, además de la posibilidad de ejercitar el derecho de opción hasta el 1 de febrero de 1988, abonando el día de su ejercicio 1960 millones de pesetas (resto del precio) con facultades resolutorias explícitas hasta el 31 de diciembre, para cuyo supuesto también se especificaban las consecuencias.

Producida una nueva situación urbanística, "Somosaguas Sur, S.A.» ejercita su derecho de opción, pero no satisface el precio estipulado por considerarse distinto al fijado inicialmente debido a la nueva situación urbanística. Ante la negativa de la otra parte de cumplir el contrato de opción, formuló demanda de mayor cuantía sobre resolución de contrato privado contra «Urbanizadora Somosaguas, S.A.». Por su parte, esta última sociedad formuló demanda de mayor cuantía contra "Somosaguas Sur, S.A.» sobre nulidad de contrato y otros pedimentos. El Juzgado de 1. ${ }^{a}$ Instancia desestimó la demanda interpuesta por "Somosaguas Sur, S.A.» y declaró resuelto el contrato con restitución a «Urbanizadora Somosaguas, S.A.», de la suma de 450 millones de pesetas.

Apelada la anterior resolución por «Somosaguas Sur, S.A.», la Audiencia estimó parcialmente el recurso en el sentido de declarar que con la devolución de la suma antes indicada se abonarán también los intereses pactados en el contrato resuelto. "Somosaguas Sur, S.A.» interpuesto recurso de casación por no aplicación del art. 1.258 del Código Civil, de modo que, producida una nueva situación urbanística, los jueces deberían pronunciarse acerca de cuál debía ser el precio que había de satisfacerse, ya que las circunstancias ajenas al contrato permitían aplicar la cláusula rebus sic stantibus. 
El Tribunal Supremo desestima el motivo:

«al no darse los presupuestos necesarios para la aplicación de la cláusula rebus sic stantibus. En efecto, a lo largo de toda la Sentencia recurrida, pro figurar en el contrato y por el examen de la prueba practicada, se sienta que Somosaguas Sur, S.A., tenía un perfecto y detallado conocimiento de la situación urbanística de las fincas objeto del contrato, asumiendo cierta alea o albur, cuyos efectos se tratan de paliar con la condición suspensiva (...) todo lo cual revela que no puede hablarse de verdadero derrumbamiento del contrato por aniquilación del equilibrio de las prestaciones, ni de sobreveniencia de circunstancias radicalmente imprevisibles ni de que se carezca de medios para salvar el perjuicio, pues lo que se pretende realmente es un nuevo contrato solicitar que se fije un nuevo precio a la opción y que valga la opción ejercitada de modo diferente a lo convenido, con alteración del principio pacta sunt servanda y de la seguridad jurídica, dejando el cumplimiento del celebrado al arbitrio de uno de los contratantes, razones todas que obligan a contemplar la cláusula rebus sic stantibus con gran cautela».

Por tanto, niega la aplicabilidad de la cláusula rebus sic stantibus a una opción de compra por entenderla contraria a la voluntad de las partes que conocían perfectamente el objeto contractual y no quisieron hacer variable el precio, asumiendo cierta alea o albur en cuanto al valor objeto de los bienes en razón del tiempo y evolución del proceso urbanístico.

Esta referencia al riesgo contractual también existe en la STS de 14 de octubre de $1999^{33}$. Así, en opinión del Tribunal Supremo el cambio de la normativa urbanística simplemente implica un evento que debe integrarse dentro del alea o riesgo que supone cualquier operación realizada a plazo, como ocurre con esta operación de futuro, ya que en caso contrario, si las condiciones urbanísticas provocan un aumento del valor de los inmuebles, no sería lógico otorgar al concedente de la opción una acción para la reclamación de diferencias.

En definitiva, lo que parece defender con ello el Tribunal Supremo es que el contrato de opción es un instrumento de reparto de riesgos, si sobrevienen determinadas circunstancias adversas, ello es un riesgo que el contrato debería haber contemplado. Desde el momento en que las partes en el contrato pretenden obtener una ga-

${ }^{33}$ Cfr. MARTÍNEZ VELENCOSO: «Contrato de opción de compra y modificación de la situación urbanística del inmueble (comentario a la STS de 14 de octubre de 1999 [RJ 1999, 7327]», RdP año I, núm. 5, 2000, págs. 185-194. 
nancia deben asumir el riesgo de que el cumplimiento devenga excesivamente oneroso.

\section{REFLEXIONES FINALES: LA IMPROBABLE APLICACIÓN DE LA CLÁUSULA REBUS SIC STANTIBUS EN LOS CONTRATOS DE OPCIÓN}

Si como pone de manifiesto la STS de 26 de julio de 1993 «la cláusula rebus sic stantibus es fruto de la equidad y del principio equilibrador de las prestaciones en los negocios onerosos", y la STS de 6 de octubre de 1987 niega la aplicación de la cláusula al derecho de superficie que «por su carácter de derecho real con virtualidad erga omnes e inscribible en el Registro de la propiedad (...) está sometido a un estatuto, cuya rigidez no encaja con las doctrinas propugnadas por la recurrente (aplicación de la cláusula rebus sic stantibus) que son propias de las relaciones negociales de índole personal dentro del campo del derecho de obligaciones».

Por aplicación de las reglas de la hermenéutica a la doctrina jurisprudencial que conforme al art. 1.6 del CC complementa el ordenamiento jurídico, la cláusula rebus sic stantibus no será aplicable a los contratos de opción de carácter gratuito, esto es aquellos en los que no haya intervenido la prima de la opción, ni tampoco a los contratos de opción de carácter real inscritos en el Registro de la propiedad en virtud de lo dispuesto en el art. $14 \mathrm{RH}$.

Como consecuencia de todo lo expuesto, podemos concluir afirmando que tras este estudio de las sentencias del Tribunal Supremo, todas ellas negativas, entendemos que resulta extremadamente difícil e improbable aplicar a los contratos de opción, por sus peculiares características, una cláusula que no está legislada y cuya admisión podría poner en peligro el principio de la seguridad jurídica contractual (pacta sunt servanda), el mantenimiento del orden jurídico y la eficacia de la voluntad manifestada, pues en caso de conflicto entre el principio de la estabilidad del contrato y el principio de la equidad, este último es el que debe primar.

\section{BIBLIOGRAFÍA}

ALGUER: «Ensayos varios sobre temas fundamentales de Derecho Civil IV. Los precontratos», RJC, 1931. 
BONET RAMÓN: Comentarios al Código Civil de Mucius Scaevola, XIII, I, 2. ${ }^{\text {a }}$ ed., Madrid, 1970.

CASTRO: «La promesa de contrato», ADC, III, 1950.

CANDIL: La cláusula rebus sic stantibus, estudio de Derecho español, Madrid, 1946.

CASTÁN: Derecho civil español, común y foral, IV, Madrid, 1988.

LALAGUNA: "La función negocial de la promesa de venta», $R C D I$, 1969.

DÍEZ-PICAZO Y PONCE DE LEÓN: «La cláusula rebus sic stantibus» en Cuadernos de Derecho Judicial, Consejo General del Poder Judicial, Madrid, 1996.

DUALDE GÓMEZ: «De la cláusula rebus sic stantibus», Conferencia Colegio Notarial de Barcelona, 1942.

JERÓNIMO GONZÁLEZ: «El llamado Derecho de opción», RCDI, 1932.

LASARTE ÁLVAREZ: Principios de Derecho civil, tomo III, contratos, Madrid, 2011.

LENEL: "La cláusula rebus sic stantibus», trad. de W. Roces en Revista de Derecho Privado, 1923, julio-agosto.

LORENZO MERINO: La opción de compra en el Derecho español, Santiago de Compostela, 1992.

MARTÍNEZ VELENCOSO: "Contrato de opción de compra y modificación de la situación urbanística del inmueble (comentario a la STS de 14 de octubre de 1999», RdP año I, núm. 5, 2000, págs. 185-194.

MEZQUITA DEL CACHO: «El pacto de opción y el derecho que origina», RDCI 1951.

MORETÓN SANZ, «Examen crítico de los fundamentos dogmáticos y jurisprudenciales de la expromisión y del artículo 1.205 del Código civil español (La vicenda modificativa, la sucesión singular de las deudas, el programa de la prestación y la aplicabilidad de ciertos principios contractuales «), Anuario de Derecho Civil, tomo LXI, fas. II, 2008, pág. 627 y 628.

OSORIO Y GALLARDO: El contrato de opción, 2. ${ }^{\mathrm{a}}$ ed., México, 1963.

OSTI: «La cossi detta clausola rebus sic stantibus nel suo sviluppo storico», Revista de Diritto Civile. 
PUIG PEÑA: Compendio de Derecho civil español, III, 3. ${ }^{\text {a }}$ ed., Madrid, 1976.

RAMÓN CHORNET: «Derecho de opción: cancelación de cargas ulteriores y breve apunte sobre su naturaleza real», RCDI 1989.

SERRANO ALONSO: «Nota sobre el derecho de opción», RDP, 1979.

TALMA CHARLES: «Crónica jurisprudencial sobre el contrato de opción relativa a la década de los noventa», $R d P$, año I, núm. 2 , 1999, págs. 557-578.

\section{X. ÍNDICE DE SENTENCIAS DEL TRIBUNAL SUPREMO}

Sentencia de 6 de noviembre de 1922.

Sentencia de 14 de Diciembre de 1940.

Sentencia de 13 de junio de 1944.

Sentencia de 17 de mayo de 1957.

Sentencia de 6 de junio de 1959.

Sentencia de 15 de marzo de 1972.

Sentencia de 16 de junio de 1983.

Sentencia de 27 de junio de 1984.

Sentencia de 19 de abril de 1985.

Sentencia de 17 de mayo de 1986.

Sentencia de 6 de octubre de 1987.

Sentencia 24 de enero de 1991.

Sentencia de 8 de marzo de 1991.

Sentencia de 23 de abril de 1991.

Sentencia de 14 de mayo de 1991.

Sentencia de 13 de noviembre de 1992.

Sentencia de 1 de diciembre de 1992.

Sentencia de 22 de diciembre de 1992.

Sentencia de 21 de marzo de 1993.

Sentencia de 18 de junio de 1993. 
Sentencia de 21 de junio de 1993.

Sentencia de 24 de junio de 1993.

Sentencia de 26 de julio de 1993.

Sentencia de 22 de septiembre de 1993.

Sentencia 18 de octubre de 1993.

Sentencia de 4 de febrero de 1994.

Sentencia de 20 de abril de 1994.

Sentencia de 14 de febrero de 1995.

Sentencia de 19 de abril de 1995.

Sentencia de 29 de mayo de 1996.

Sentencia 14 de febrero de 1997.

Sentencia de 16 de octubre de 1997.

Sentencia de 4 de diciembre de 1997.

Sentencia de 15 de diciembre de 1997.

Sentencia de 22 de abril de 2000.

Sentencia de 20 de febrero de 2001. 
